\title{
Research on Data Analysis of Chinese Public Accounting Firms in the Big Data Era
}

\author{
Meng Kang, Fuangfa Ampornstira* \\ School of Management, Shinawatra University, Bangkok, Thailand \\ Email: km0518@163.com, ^fuangfa.a@siu.ac.th
}

How to cite this paper: Kang, M., \& Ampornstira, F. (2021). Research on Data Analysis of Chinese Public Accounting Firms in the of Big Data Era. Open Journal of Accounting, 10, 1-8.

https://doi.org/10.4236/ojacct.2021.101001

Received: April 4, 2020

Accepted: December 25, 2020

Published: December 28, 2020

Copyright (อ 2021 by author(s) and Scientific Research Publishing Inc. This work is licensed under the Creative Commons Attribution International License (CC BY 4.0).

http://creativecommons.org/licenses/by/4.0/

\begin{abstract}
The rapid development of computer and Internet technology has brought human society into the era of information technology, and it has a profound impact on human's past work, production, management and consumption methods (AICPA, 2014). Even the social economic structure has changed in this general environment. With the rapid development of information technology, tradition has been unable to meet current needs. By combining the concept of big data and the characteristics of audit work in the era of big data, this article explores the effective countermeasures for optimizing the data analysis in the era of big data (Richins et al., 2017).
\end{abstract}

\section{Keywords}

Big Data Audit, Data Analysis, Public Accounting Firms

\section{Introduction}

With the continuous penetration of the Internet concept, modern information technologies such as computers, servers, databases, optic fiber network, and communication technology (especially the 5G technology is getting more and more mature) have been widely used in social practice activities, and they have played an important practical role in different fields (Clatworthy et al., 2020). Based on the concepts of energy conservation and environmental protection, the efficient use of resources has become a necessary condition for enterprises and government agencies. At the same time, audit resources and evidence clues are also moving towards paperlessness, the scope of the audit is further extended to the electronic data, internal control system, and information system (Adrianto, 2018). All these indicate that auditing must adapt to the current digitization and information flow conversion to ensure that audit efficiency and quality supervision functions are fully utilized (Sjöberg \& Johansson, 2016). These changes have 
prompted the audit work that takes audit accounting books and corresponding economic activity materials as the main forms to face huge challenges (Appelbaum et al., 2017).

\section{The Concept of Big Data}

Based on big data, Gartner research institute put forward this definition: big data refers to the collection of data that cannot be processed, captured and managed by conventional software tools within a certain period of time, but requires new processing modes to have strong insights Discovery power, decision-making power, and process optimization capabilities to adapt to high growth rates, massive and diverse information resources (Li \& Gong, 2015).

The McKinsey Global Institute (2011) put forward this definition: a data collection that is so large that it exceeds the level of previous database software tools in terms of acquisition, storage, management, and analysis. It has high-speed data transfer, massive data scale, and multiple data types.

Yuan Ye (deputy auditor of the China National Audit Office) believes that big data provides rich data resources and full-dimensional intelligent analysis perspective for audit work, and also brings a series of difficulties and challenges to the audit work.

A definition also appeared in the research report of Doug Laney-an analyst of the IT analysis company META Group (now acquired by Gartner) in 2001. Doug Laney noticed that the growth of data is three-dimensional, that is, capacity, diversity, and speed. The same viewpoint is three characteristics of big data-volume, variety, and velocity (Zikopoulos \& Eaton, 2011). The definition of $3 \mathrm{Vs}$ is still being expanded. To describe big data, authors at Gartner and most industry giants such as IBM and Microsoft continue to use the " $3 \mathrm{Vs}$ " model to describe big data. In general, big data has four characteristics: Volume, Variety, Velocity, and Veracity (Chen et al., 2012). Later, in the big data Value book published by IBM, the ultimate impact of big data is to realize its true value (Mike, 2014).

\section{Characteristics of Audit Work in the Era of Big Data}

\subsection{Comprehensive Audit Content}

Four-fifths of China's useful data is controlled by the government, but it has been kept secret for a long time. In the past, it was very difficult for enterprises to obtain macroeconomic data. In February 2016, the General Office of the State Council issued the "Opinions on Comprehensively Promoting the Openness of Government Affairs," which called for accelerating the construction of a centralized and open platform to realize the large-scale disclosure of government data. The disclosure of government data encourages and promotes the in-depth analysis and application of government public data. After processing a large amount of government basic data, it can be transformed into a market-competitive resource to realize its attached economic value and be applied to big data (Gepp et 
al., 2018). Analysis creates wealth for the enterprise. With the enterprise big data platform, enterprises can easily obtain macro data that was previously difficult to obtain (Chen et al., 2012).

Cloud computing, the Internet, and big data reduce the cost of companies to acquire and use information data, and enable audit departments to fully and timely grasp internal data. With the help of Internet technology, auditors can easily obtain data related to the audited events, including internal data and external data. On the one hand, external data covers: government data and economic data disclosed by government departments according to law, as well as many data disclosed by companies according to law, etc. This provides certain data support for the evaluation and supervision of auditors. On the other hand, at the level of internal data acquisition, enterprises can use big data technology to classify, summarize and store many data related to production operations, financial data and business data formed in the operation of the enterprise.

The audit database is generated. Based on this, enterprises can no longer be limited to single item and financial level audits in audit work, and the audit object has also changed from random sampling to full sample, which in turn makes the audit sample more comprehensive. The information silos that exist between the audit department and the audited unit and between the various departments of the enterprise will be truly broken, which will help the audit department to break through the professional industry data and correlation analysis and multi-angle analysis to break the current departmental constraints, improve the ability to obtain evidence and discover hidden clues, and strengthen the combat effectiveness of audit departments.

\subsection{The Continuity of the Audit Process}

In the information environment, auditors generally collect electronic data from the audited company according to the needs of the audit task, and then preprocess the electronic data and complete the data analysis to obtain audit evidence. This method of conducting electronic data auditing can be called on-site electronic data audits. At present, the audited unit has a high degree of informationization, and the information system is involved. There are many types of data to be collected, not only structured electronic data in the database, but also some meeting records, meeting resolutions, official notices, office documents, and unstructured data such as policies, internal control manuals, and individual system manuals. Different from the traditional data audit, the audit activity under the characteristics of big data environment is a big data audit. Therefore, the audit work is inextricably linked with big data. In the electronic data audit work, the data is very important to the auditors, and the audit process is also a process of "speaking with data and making decisions with data." The development of information technology has made audit informationization develop in a continuous, dynamic, and real-time direction (Byström, 2019).

Continuous auditing (CA) has become an important development direction of audit informationization; to obtain audit evidence, it is not difficult to find that, 
compared with on-site electronic data auditing, the principle of networked auditing can be regarded as a process of collecting electronic data from the audited company by remote networking and analyzing. The application of networked auditing technology has accumulated a large amount of electronic data for auditing units, which provides conditions for conducting audit big data analysis (Kuhn Jr. \& Sutton, 2010). It can be seen that continuous auditing has laid the foundation for the development of big data auditing (Zhang, Yang, \& Appelbaum, 2015).

The academic field has been exploring continuous auditing for many years, but it has relied on it for a long time. Due to the constraints of information technology conditions and level quotas, this auditing method has not been implemented in real work. In the context of big data, the continuous development of information technology provides a technical basis for China's continuous audit work, and promotes the continuous audit from the previous assumptions into reality. The continuity of the audit process is characterized by its "continuity". The enterprise audit department can continuously obtain business-related business data and financial data, and perform special audits, risk prevention and control, and continuous monitoring and other tasks to implement The risks in the business link are continuously monitored and audited, and the internal operation risks and financial risks of the enterprise are effectively reduced.

\subsection{Audit Management Intelligence}

The intelligent features possessed by audit management run through the entire process of audit work, covering the design of early audit programs and the allocation of audit resources, and the implementation of audit tasks in the event development. Sorting, refining, secondary utilization of post-audit results and real-time inspection of the auditee's rectification status and audit management is intelligent. During the audit planning period, the formation of the audit plan mainly stems from the continuous monitoring of the doubtful point database, risk database, and problem database formed by the actual auditing system to strengthen the accuracy of the audit work. During the period of audit organization, the audit system will reasonably allocate related work according to the content of the audit work and the status of the audit workers, appropriately allocate manpower, material and financial resources, and maximize the use of audit resources. During the period of audit execution, auditors can use special data information analysis models and general data analysis APPs to analyze problems, and automatically generate relevant audit papers to promote the standardization and standardization of audit execution, and can also greatly reduce audit workload. On the other hand, in the management of the audit process, the audit system will continuously monitor the progress of the audit work, grasp the status of audit work practice, coordinate and coordinate audit resources, and enhance audit effectiveness. In addition, the audit work will fulfill the standardized and standardized document format content and business process, implement all-round quality control of the audit work, optimize the actual quality of 
the audit report, and help the audit work quality inspection and supervision.

\section{Effective Countermeasures for Optimizing Audit Data Analysis in the Era of Big Data}

\subsection{Building a Sound Audit System}

In the context of the era of big data, audit companies have also changed at the level of economic activity. The most notable is that the e-commerce industry is more frequent at the level of economic interaction, and this has also caused the difficulty of collecting information data from audit departments (Chen \& Smieliauskas, 2017). Under this situation, enterprises should build a sound audit system and conduct comprehensive audits of digital certification organizations (Ho-Quang et al., 2020). For management and legal qualifications, they can be raised to the legal level and unified management. In addition, the relevant audit department should also build relevant systems based on the actual situation of the audit work, continue to explore enterprise audit methods that can meet the current era of big data, and build certain targeted standard regulations in the audit system. In this way, not only can the idea, process, experience, and means of audit data analysis work in the context of big data be clear, but it can also effectively prevent unnecessary problems in the collection of audit worker data information (Ji, 2017).

The results indicate that five aspects of big data have relatively significant impacts on auditing, including big data collection, big data mining, big data integration, big data storage, and big data analysis. This is manifested by the use of information technology that brings updates to auditing (Adrianto, 2018).

\subsection{Increase Management of Big Data}

Ensuring the security of audit data information is the basic condition for audit data analysis in the context of big data. Auditors, while making full use of the advantages of big data technology, should also increase their investment in human, financial and material resources in their work to strengthen the security management of data and information. On the one hand, strengthen the management of the storage platform of audit data information, design a reasonable and scientific management mechanism according to the current status of the platform, and carry out according to the management system in the storage of data information, and then guarantee the true security of data information. On the other hand, build a data information analysis system, which can analyze the relevant data contained in the data information storage platform (Sjöberg \& Johansson, 2016).

Data transmission is safe (Xu \& Duan, 2019). In addition, it implements hierarchical management of audit data, establishes relevant authorization for data information, and then guarantees the security of all levels of data information, and should take targeted protection measures against sensitive data to prevent theft or tampering of data information. 


\subsection{Strengthen the Comprehensive Quality of Auditors}

As far as the current situation is concerned, the audit work is mainly conducted by audit business workers, but most of the workers themselves have low auditing ability and cannot meet the standards required by enterprises or auditing work themselves. Under the background of big data, the phenomenon of unqualified auditors will inevitably hinder the audit work. Due to the lack of audit-related professional knowledge and unskilled technical practice, the length of the audit work has been greatly extended. However, professional program writing workers, professional data analysis workers, professional statistical analysis workers, etc., are all necessary for a relatively complete audit team. Only in this way can audit work keep up with the times and social development. Therefore, enterprises should improve the construction of audit work teams and attract professional talents by increasing salary and treatment. At the same time, enterprises should also improve the professional quality of internal auditors and use diversified training activities to strengthen the data processing level and business literacy of auditors. And in order to promote internal auditors to actively participate in training to learn new knowledge and new technologies, enterprises can create an evaluation system to assess the learning situation of auditors in real time within a certain period of time, thereby prompting the audit to quickly adapt to the big data technology environment. In addition, we should also innovate the audit concept. Auditors should innovate past thinking patterns, dare to apply many modern and informatization software, extensively collect information data to create databases, analyze and evaluate their relevance, and make judgments based on the analysis results and actual conditions.

\section{Conclusion}

To sum up, audit data analysis is a relatively long and complicated project, so it will be improved along with the progress of information technology, but if you want to ensure the smooth and stable execution of audit data analysis, you should focus on audit data, analyze the risks and problems in the work and adopt efficient and scientific coping strategies in a timely manner. In addition, the corresponding departments should strengthen the emphasis on audit work in the context of big data. In the aspects of building a complete audit system, strengthening big data management and enhancing the comprehensive quality of auditors, the audit department puts forward strategies to reduce the risks and problems in audit work. This research proposes solutions to the advantages and challenges of auditing currently faced by big data, but based on limited research, it fails to explain in depth how this measure works.

\section{Conflicts of Interest}

The authors declare no conflicts of interest regarding the publication of this paper. 


\section{References}

Adrianto, Z. (2018). Auditing in the Era of Big Data: A Literature Review. Jurnal Akuntansi dan Keuangan, 17, 7-12.

AICPA (2014). Reimagining Auditing in a Wired World (White Paper). Now York: American Institute of Certified Public Accountants.

Appelbaum, D., Kogan, A., \& Vasarhelyi, M. A. (2017). Big Data and Analytics in the Modern Audit Engagement: Research Needs. Auditing: A Journal of Practice \& Theory, 36, 1-27. https://doi.org/10.2308/ajpt-51684

Byström, H. (2019). Blockchains, Real-Time Accounting, and the Future of Credit Risk Modeling. Ledger, 4, 40-47. https://doi.org/10.5195/ledger.2019.100

Chen, W., \& Smieliauskas, W. (2017). Electronic Auditing Method Based on Data Visualization Technology in Big Data Environment. Chinese Certified Public Accountant, No. 1, 101-106.

Chen, W., Liu, S. F., Smieliauskas, W. et al. (2012). Influence Factors Analysis of Online Auditing Performance Assessment: A Combined Use between AHP and GIA. Kybernetes, 41, 587-598. https://doi.org/10.1108/03684921211243257

Clatworthy, M., García Lara, J. M., \& Lee, E. (2020). 50 Years of Accounting and Business Research. Accounting and Business Research, 50, 1-5. https://doi.org/10.1080/00014788.2020.1690742

Gepp, A., Linnenluecke, M. K., O’Neill, T. J., \& Smith, T. (2018). Big Data Techniques in Auditing Research and Practice: Current Trends and Future Opportunities. Journal of Accounting Literature, 40, 102-115. https://doi.org/10.1016/j.acclit.2017.05.003

Ho-Quang, T., Chaudron, M. R., Hebig, R., \& Robles, G. (2020). Challenges and Directions for a Community Infrastructure for Big Data-Driven Research in Software Architecture. In Model Management and Analytics for Large Scale Systems (pp. 13-35). Cambridge, MA: Academic Press. https://doi.org/10.1016/B978-0-12-816649-9.00010-7

Ji, X. D. (2017). Development of Accounting and Auditing Systems in China. Abingdon-on-Thames: Routledge. https://doi.org/10.4324/9781315210124

Kuhn Jr, J. R., \& Sutton, S. G. (2010). Continuous Auditing in ERP System Environments: The Current State and Future Directions. Journal of Information Systems, 24, 91-112. https://doi.org/10.2308/jis.2010.24.1.91

Li, X. L., \& Gong, H. G. (2015). Overview of Big Data System. Chinese Science and Information Science, No. 1, 144.

Luo, J., Meng, Q. and Cai, Y. (2018) Analysis of the Impact of Artificial Intelligence Application on the Development of Accounting Industry. Open Journal of Business and Management, 6, 850-856.

McKinsey Global Institute (2011).

Mike 2.0 (2014). Big Data Definition-Mike 2.0.

Richins, G., Stapleton, A., Stratopoulos, T. C., \& Wong, C. (2017). Big Data Analytics: Opportunity or Threat for the Accounting Profession? Journal of Information Systems, 31, 63-79. https://doi.org/10.2308/isys-51805

Sjöberg, P., \& Johansson, M. (2016). Shaping the Future of the Auditing Profession in Sweden: A Study of the Expected Role of Digitalization.

Xu, L. D., \& Duan, L. (2019). Big Data for Cyber Physical Systems in Industry 4.0: A Survey. Enterprise Information Systems, 13, 148-169. https://doi.org/10.1080/17517575.2018.1442934

Zhang, J., Yang, X., \& Appelbaum, D. (2015). Toward Effective Big Data Analysis in Con- 
tinuous Auditing. Accounting Horizons, 29, 469-476.

https://doi.org/10.2308/acch-51070

Zikopoulos, P., \& Eaton, C. (2011). Understanding Big Data: Analytics for Enterprise Class Hadoop and Streaming Data. New York: McGraw-Hill Osborne Media. 